\title{
The substantiation of regulatory requirements to the reliability of consumer support in the conditions of the perspective planning of the UPS of Russia
}

\author{
Yuri Chukreyev ${ }^{1, *}$, Mikhail Chukreyev ${ }^{1}$, and Alexey Stepskov ${ }^{1}$ \\ ${ }^{1}$ Komi Scientific Center of the Ural Branch of the Russian Academy of Sciences, ISE and EPN, 167000, Russia
}

\begin{abstract}
The issues of the influence of the information content of the balance reliability problem on the decisions taken to justify the operational power reserve of the UPS of Russia are considered. The calculated indicators of adequacy are presented with different representation of the power consumption and generating capacity for the conditions of the optimal distribution of the power reserve.
\end{abstract}

\section{Concepts of the regulatory reserve of capacity in the balance of capacity of the power system}

When planning the development of the industry, the socalled balance of power for the UPS of the country as a whole and its unified electric power system (UPS) [1,2] was developed earlier, is being developed today and will be developed in the future. Its form includes two positions (Figure 1): the expenditure part "demand" (maximum load, export and standard power reserve); the incoming "cover" (installed power, unused power for the period of passage of the maximum, power inputs after passing the maximum, underutilization of power).

The issue that concerns both consumers and suppliers of electrical energy is to justify the regulatory power reserve, which is one of the components of the expenditure part of the balance sheet. In the tasks of long-term planning of EPS it is called the full (normative) reserve, and conditionally divided into three components: repair, strategic and operational, intended to compensate for unscheduled (emergency) conclusions of the main generating and network equipment for repair. Therefore, in order not to confuse the concept of operational reserve in the current planning and shortterm (long-term), this component of the full reserve has recently been called the compensation reserve.

Repairing power reserve is made to compensate power generating equipment of power plants that is going to be maintained according to the schedule (average, current and capital). Compensatory reserve is used to compensate: decrease of power generators at electric power stations in emergency situations, occasional excess load of electricity consumption. This might be caused by the forecast errors and temperature variations. Therefore, the compensation reserve is divided into emergency and loaded. These components can be considered independent that simplifies the solution of the problem of the justification of the normalized power reserve a lot.
Market relations in the electric power industry exacerbate the issues of justifying the power reserve. With short-term planning (from one year to 4 years), the price for capacity during long-term (competitive) power

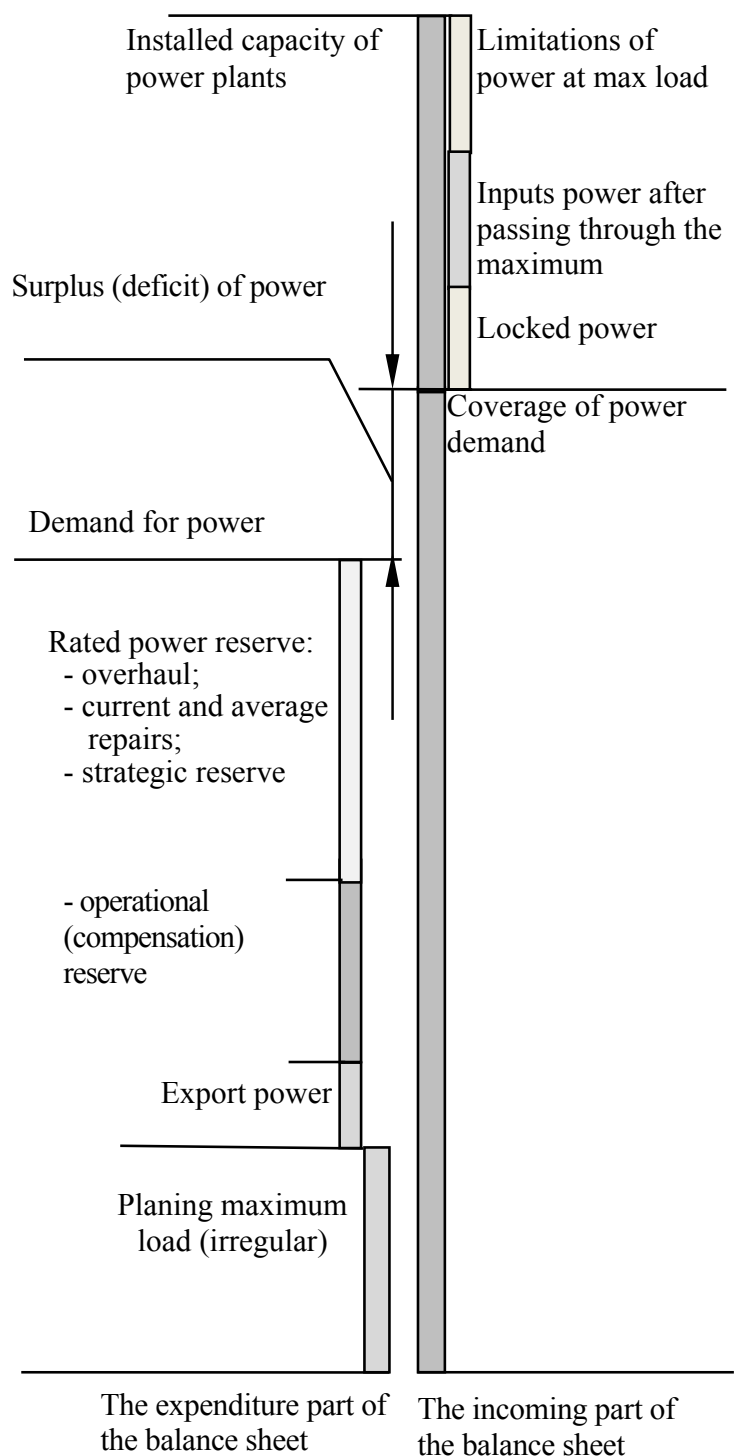

Fig. 1 - Structure of the projected balance of power. 
take-off depends on the requirements for a full (normative) reserve in the conditions of market relations. There is a conflict of interests between power supply companies and consumers of electricity.

If the repairing power reserve is determined on the basis of the analysis of statistical information on the operation of the main equipment or the rules for their organization $^{1}$, strategic - expert, then the definition of the operational (compensation)power reserve requires the solution of the task of assessing the indicators of adequacy (IA). The regulatory definition of reserve generating power is difficult mainly due to the need to find compensatory power reserve [3 - 6 , etc.].

The basis for determining the requirements for power reserve in the development of prospective balances was, is and will be the task of assessing the indicators of balance reliability of development options of the UPS of Russia, the so-called reliability analysis problem. Regardless of the management principles of the electric power industry (centralized or market), the methodology for its solution involves the implementation of two phases. On the first, by some other methods random states of generating power are generated, caused by emergency outputs of equipment and load due to its random changes due to forecast errors. At the second stage, these states are evaluated from the standpoint of a possible restriction of consumers due to the impossibility of achieving a power balance.

The shortage of power to the consumer and the damage caused by this phenomenon are usually more expensive than purchasing power regardless of the form of management (market or centralized management) by the industry. This leads to the following. At each state of the system, a power shortage in the UPS of Russia is possible in cases of (emergency exit of the main generating and network equipment, random load changes): a shortage of generating capacity; lack of stocks of communication capacities; one and the other together. Therefore, we can say that the problems characteristic for solving the problem of estimating the indicators of balance reliability in the conditions of market relations practically do not differ from those in the conditions of the centralized management principle of the UPS of Russia. Differences can only concern the issues of distribution of system power deficiency between the territorial zones of the model of the settlement scheme of the UPS of Russia. Thus, under the conditions of liberalization, the traditional formulation of the task of ensuring balance reliability remains. Balance reliability is provided due to the optimal development of generating capacities and reserves of the capacity of system-forming links.

\section{Indicators of adequacy and their normative values in our country and abroad}

1 SO 34.04.181-2003. Rules for the organization of maintenance and repair of equipment, buildings and structures of power plants and networks (http://regulation.gov.ru)
At the present stage, the most acceptable IA from the standpoint of justifying the means of ensuring reliability (compensation capacity reserve) are considered [5-7]:

- In the domestic practice, the probability of deficit-free operation of territorial zones of the EPS $\left(\rho=1-J_{\text {д }}\right)$, where $J_{д}$ is the integral probability of power shortage;

- the average number of days of power shortage (loss of the anticipated load - LOLE [2]);

- the average number of hours per year of power shortages (loss of load hours - LOLH).

At us in practice of designing till now the standard to probabilistic indicators of balance reliability $\bar{\rho}=0,996$ is applied. In developed countries the minimum value of power reserve from unplanned changes must also correspond to some pre-selected probability targets. Some of the normative values of $L O L E$ and $L O L H$ exist have at the expert level in North America and Western Europe have. They serve as indicators in decisionmaking. In the United States and Canada the minimum amount of reserve power in these countries should correspond to the index of adequacy is not higher values of $L O L E=0,1 \mathrm{~d} /$ year. Common standards for some European countries [12]: France $L O L H=3 \mathrm{~h} /$ year, the $\mathrm{UK}$ and the Netherlands $-L O L H=4 \mathrm{~h}$ /year, Ireland $L O L H=8 \mathrm{~h} /$ year.

\section{Problematic issues of justification of the standard reserve capacity in relation to modern conditions for planning the development of power systems}

The justification of the reserves of capacity of the territorial zones of the UPS of Russia when managing their development, in modern conditions, should be directed to the application of methodological approaches aimed at minimizing the functional of the resulted costs $3_{\Sigma}(\Pi)$ with the obligatory performance of the normative indicators of balance reliability.

$$
3_{\Sigma}(\Pi)=3_{R}(\Pi)+3_{L}(\Pi)->\min , \text { npu } \rho(\Pi)>\bar{\rho},
$$

where

$$
3_{R}(\Pi)=\sum_{j=1}^{n} 3_{R_{j}}^{\text {уд. }} R_{j}, 3_{L}(\Pi)=\sum_{l=1}^{m} 3_{L_{l}}^{\text {уд. }} P_{l}^{L}
$$

respectively, the reported costs for the maintenance of reserves of generating capacity $\left(R_{j}\right) j$-th territorial zones and throughput $\left(P_{l}^{L}\right) l$-th communication; $3 \frac{\text { уд. }}{R_{j}}, 3 \frac{\text { уд. }}{L_{l}}-$ unit costs (rub / $\mathrm{kW}$ ), respectively, to create a reserve for generation of capacity in the $j$-th territorial area of EPS and to strengthen ties; $\rho(\Pi), \bar{\rho}$ - accordingly, the indicators of adequacy given the means to ensure reliability (П) and their normative significance.

The use of standards for the indicators of balance reliability is due to the difficulty of obtaining information on compensation costs from unreliability (damages). At the same time, the question arises of 


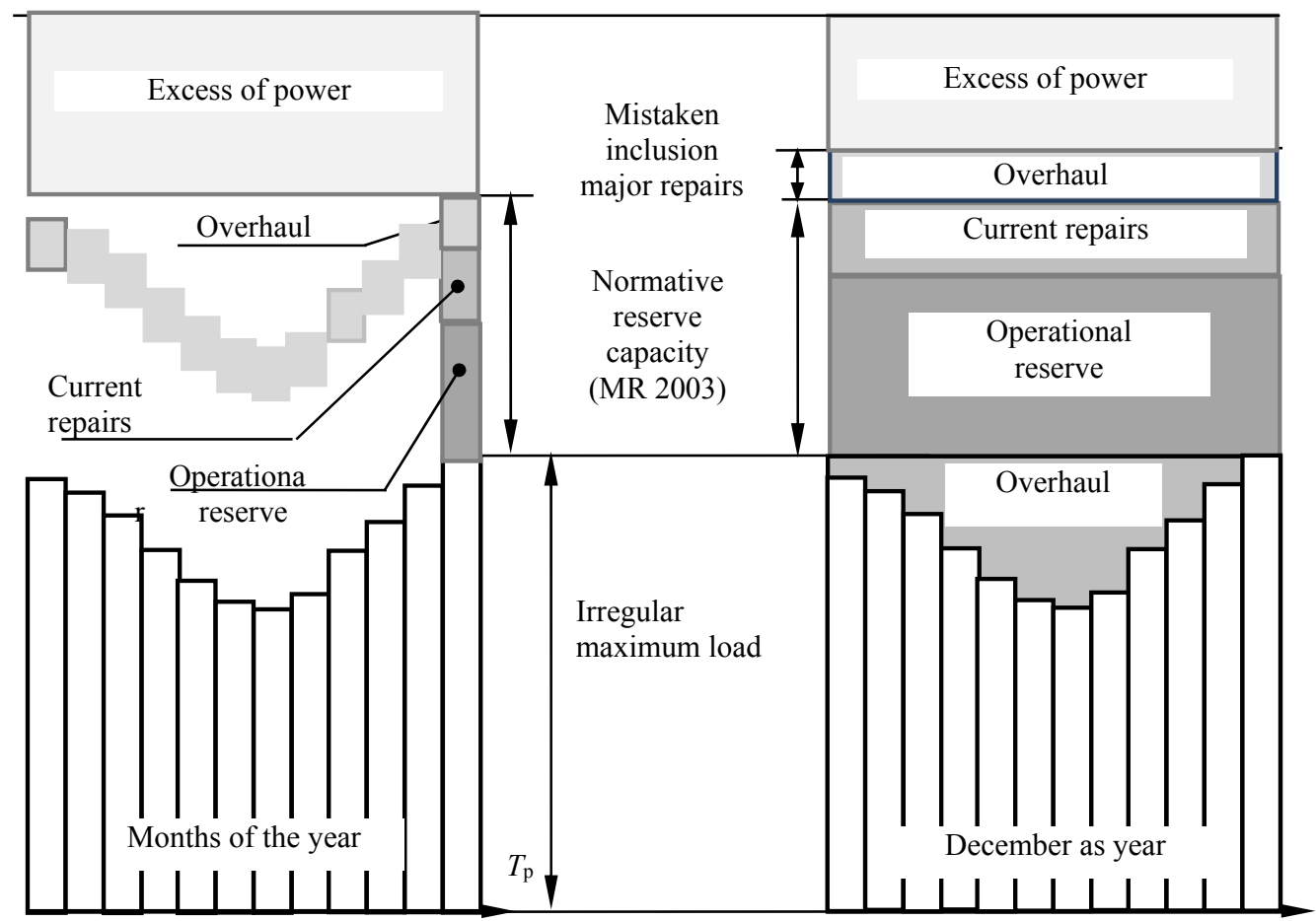

Fig. 2. Effect of simplifications in the representation of the power consumption mode in the justification of the operational (compensation) power reserve.

on the left - carrying out major repairs evenly for the seasons of the year; right - the inscription of capital repairs in seasonal failure.

determining the numerical value of the standard for estimating the balance sheet reliability indicators $\bar{\rho}$ for making decisions on the justification of power reserves in the territorial UPS of Russia. In the domestic practice of planning the development of the country's UPS $[1,2]$ for these purposes, the reliability factor was used in the form of the probability of a deficit-free work $\bar{\rho}=0.996$.

This corresponds to the integral probability of power shortage of a power deficit in the $j$-th territorial zone of the UPS of Russia $J_{\text {माr. }}^{\text {опा }}=0.004$.

The connection of the indicator $J_{\mu}^{\text {onr. }}$ used in Russia since the 1980s with the LOLH load loss indicators in hours and especially LOLE in the day is quite complicated. The article considers only the issues of comparing the domestic indicator with the LOLH index. Important from the standpoint of justifying the operational reserve of capacity is the understanding of two mutually affecting each other moments. The first is that in our country when planning the development of the UPS of Russia, information on the years of the prospective period is reduced to the period of maximum loads of December ${ }^{2}$. That is why in the practice of

\footnotetext{
2 Decree of the Government of the Russian Federation of December 27, 2010, No. 1172 (Edited on 19.01.2018) "On Approval of the Rules for the Wholesale Electricity and Capacity Market and on Amending Certain Acts of the Government of the Russian Federation on the Organization of the Wholesale Electricity and Capacity Market".

Order of the Ministry of Energy of Russia dated 07.09.2010, No. 431 (Ed., Dated August 17, 2017) "On approval of the Regulation on the procedure for determining the demand for capacity for long-term power take-off on a competitive basis in the wholesale electricity (capacity) market and the procedure
}

calculating the indices of balance reliability of the territorial zones of the UPS of Russia various simplifications are applied. One of them is the submission of the settlement year by one daily schedule of December lasting all 250 working days.

The second moment of justifying the power reserve, without which the application of the first one would be impossible, consists in using the principle of capital repairs of generating equipment during periods of seasonal load reduction (Figure 2, right). This, with a certain degree of reliability, allows us to assume that the average December daily load schedule lasts the whole year.

By the third moment, which is not directly related to the first two, the composition of the generating equipment used to justify the operational (compensating) power reserve should be included. Unfortunately, in all software complexes used in national practice, estimates of the balance reliability indicators use the principle of independence in determining the components of the operational (compensation) and repair capacity reserves. This leads to the fact that when building a generation model that takes into account the composition of the generating equipment and possible its withdrawal into emergency unscheduled repair, equipment and equipment that is not used in the balance sheet and put out for scheduled repairs (even in December) are present. Not taking into account these features adds

for determining the planned coefficients reserve capacity in zones (groups of zones) of free flow of electrical energy (power) "(Registered in the Ministry of Justice of Russia on 29.09.2010, No. 18578) 
inaccuracy in the solution of the problem of justifying the reservation in the UPS of Russia.

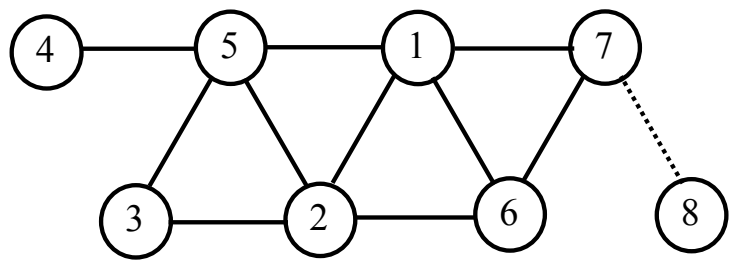

Fig. 3. Model of the settlement scheme of the UPS of Russia.

1 - UPS Urala; 2 - UPS of the Middle Volga;

3 - UPS of the South; 4 - UPS of the North-West;

5 - UPS of the Center; 6 - Kazakhstan;

7 - UPS of Siberia; 8 - UPS East.

In Table 1, the results of the influence of the abovementioned moments on the amount of the operational (compensation) power reserve are presented. The results are given for the model of the settlement scheme of the UPS of Russia, represented as a unified power plant (Figure 3). In the first line, for clarity, information is given on the irregular maximum of the load, applied to the year 2022 considered from the work of the Russian Unified Power System of Russia for 2016-2022. Lines 2 and 5 show the results of the distribution of the operational (compensating) power reserve when the norm $\bar{\rho}=0.996$, for two variants of the power consumption mode representation.

The first (line 2) consisted in optimizing the distribution of the operational power reserve when presenting the power consumption mode in the form of a single average load schedule for December, lasting all 250 working days of the year (Figure 2, right). Probabilistically determined information about the operation of the generating equipment and random deviations of the power consumption mode for this option was obtained by the specialists of SO UPS JSC and is presented in the work ${ }^{3}$ and [8]. In the calculations of the justification for the means of reserving the territorial zones of the UPS of Russia, the provisions of the 2003 LR were fully implemented in this version [1]. At the same time, this and the second version did not take into account the impact of the actual generation equipment, due to the non-use of excess capacity and the withdrawal of part of the generating equipment for scheduled repairs. This will be discussed separately below.

In the second variant (line 5), optimization of the distribution of the operational power reserve taking into account compliance with the normative indicator of adequacy $\bar{\rho}=0.996$ was performed when the electricity consumption mode was presented taking into account its seasonal decline by the month of the year (Figure 2, left). In this case, almost the same probabilistically determined

\footnotetext{
${ }^{3}$ Report on R \& D "Substantiation of the normative values of the components of the total reserve capacity in the context of the UPS and UPS of Russia as a whole in the planning of their development". - Syktyvkar: ISEiEPS Komi Scientific Center of the Ural Branch of the Russian Academy of Sciences (on behalf of JSC "SO UPS"). 2016. - 66 p.
}

information about the operation of the generating equipment and the random deviations of the power consumption regime was used, as for the first variant. It is clear that according to the power consumption regimes this information was to undergo certain changes (in the summer months, there are less random deviations, the throughput capacity will change, etc.), but it is adopted unchanged. Seasonal (monthly) reduction of the load relative to the December maximum is also assumed conditionally, based on the data available to the authors on the UPS of the North-West.

The probabilistic indicators of the balance reliability of the territorial zones of the UPS of Russia shown in lines 3 and 6 for the optimal variants for the placement of operational (compensating) power reserves with different representations of the electric power consumption regime are of no practical interest. It can be seen that these indicators are close to the normative value adopted in our country for $j$-th territorial zones $J_{\text {д }_{j}}^{\text {опт. }}=0.00418$. At the same time, the LOLH load loss indicator obtained in the course of examining 8760 steps of the annual load schedule is determined by simply multiplying the indicator $J_{\text {म }_{j}}^{\text {oпr. }}$ by $8760 \mathrm{~h}$, which leads to its approximate value of $36.5 \mathrm{~h} /$ year (lines 3 and 6 Table 1).

Attention is drawn to the significant decrease in the optimal value of the operational reserve of power when the mode of power consumption is changed from those shown in Figure. 2, right to left. According to UPS of Russia as a whole, the decrease in the size of the operative (compensating) power reserve was 2.33\% (from $10.02 \%$ to $7.69 \%$ - lines 2 and 5), in territorial zones about the same figures. Their comparison of these two lines shows how much the impact of the submission of the electricity consumption regime on the decisions taken to justify the magnitude of the operational (compensation) power reserve in the UPS of Russia.

Consider now the 4th line of Table 1, in which the mode of power consumption is changed for the received using the average daily schedule of December, lasting 250 working days of the year (Figure 2, on the right), of the power reserve allocation. Electric power consumption is represented by 12 months with characteristic daily hourly graphs (Fig. 2, left). A kind of this approach with a certain degree of reliability is the simulation of 8760 hourly changes in the load during the year. It is seen how significant in relation to row 3 of Table 1, the probabilistic indicators of balance reliability of the territorial zones of the UPS of Russia have changed. 
Table 1. Probabilistic indicators of balance reliability for the optimal distribution of the value of the operational (compensating) capacity reserve in UPS of Russia for various views of the electricity consumption regime

\begin{tabular}{|c|c|c|c|c|c|c|c|}
\hline \multirow{2}{*}{ Indicators } & \multirow{2}{*}{$\begin{array}{c}\text { UPS } \\
\text { Russia without } \\
\text { UPS } \\
\text { East }\end{array}$} & \multicolumn{6}{|c|}{ Name of UPS } \\
\hline & & Ural & $\begin{array}{c}\text { Middle } \\
\text { Volga }\end{array}$ & South & Northwest & Centre & Siberia \\
\hline
\end{tabular}

1. Irregular peaks in accordance with the Scheme and program of development the unified Power System of Russia for 2016-22.

\begin{tabular}{|l|l|l|l|l|l|l|l}
\hline 2022 year, MW & 155680 & 37930 & 17096 & 16831 & 15151 & 39266 & 30126 \\
\hline
\end{tabular}

2. The operational reserve of power when using the power consumption mode in the form of a schedule for December, which lasts all year (Figure 2, right), normative IA $J_{\text {माj }_{j}^{\text {опт. }}=0.004}$

\begin{tabular}{|c|l|l|l|l|l|l|l|l|}
\hline Power reserve, MW & 15610 & 4894 & 1078 & 1619 & 1629 & 3365 & 3025 \\
\hline \multicolumn{2}{|c|}{$\%$} & 10,02 & 13,09 & 6,31 & 9,62 & 10,75 & 8,57 & 10,04 \\
\hline 3. Balance sheet reliability indicators using this condition power consumption mode \\
\hline$J_{\text {माj. }^{\text {пाт. }}}$ & 0,00836 & 0,00419 & 0,00417 & 0,00417 & 0,00419 & 0,00418 & 0,00419 \\
\hline LOLH & 73,26 & 36,69 & 36,54 & 36,54 & 36,70 & 36,65 & 36,66 \\
\hline
\end{tabular}

4. Balance sheet reliability indicators when using other load graphs (12 seasons with one daily load profile)

\begin{tabular}{|c|c|c|c|c|c|c|c|}
\hline$J_{\text {मj }_{j}}^{\text {опт. }}$ & 0,00307 & 0,00082 & 0,000818 & 0,00082 & 0,000821 & 0,00082 & 0,000827 \\
\hline$L O L H$ & 26,99 & 7,27 & 7,23 & 7,28 & 7,26 & 7,26 & 7,30 \\
\hline
\end{tabular}

5. The operational power reserve at use of daily schedules of 12 months (fig. 2 , at the left) normative IA $J_{\mathbb{д}_{j}}^{\text {orr. }}=0,004$

\begin{tabular}{|c|c|c|c|c|c|c|c|}
\hline Power reserve, & 11985 & 3894 & 678 & 1204 & 1254 & 2565 & 2400 \\
\hline$\%$ & 7,69 & 10,42 & 3,97 & 7,15 & 8,28 & 6,51 & 7,97 \\
\hline \multicolumn{8}{|c|}{ 6. Balance sheet reliability indicators using this power mode representation condition } \\
\hline$J_{\text {дाj }}^{\text {опт. }}$ & 0,007964 & 0,00421 & 0,00416 & 0,00417 & 0,00418 & 0,00417 & 0,00420 \\
\hline$L O L H$ & 63,983 & 37,14 & 36,72 & 36,78 & 36,86 & 36,79 & 37,03 \\
\hline \multicolumn{8}{|c|}{ 7. Balance sheet reliability indicators when using other load graphs (daily schedule for December, lasting all year) } \\
\hline$J_{\text {म }_{j}}^{\text {oпt. }}$ & 0,02706 & 0,0200 & 0,0199 & 0,0198 & 0,200 & 0,0199 & 0,0198 \\
\hline$L O L H$ & 237 & 175 & 174 & 173 & 175 & 174 & 173 \\
\hline
\end{tabular}

8. The operational power reserve when using the power consumption mode in the form of the schedule of December, which lasts the whole year (figure 2, right), normative IA $J_{\mathbb{д}_{j}}^{\text {onr. }}=0.004$ for the conditions of accounting for the dependence of scheduled and unscheduled repairs

\begin{tabular}{|c|c|c|c|c|c|c|c|c|}
\hline Power reserve, & MW & 14100 & 4411 & 970 & 1441 & 1502 & 3031 & 2744 \\
\hline & $\%$ & 9,05 & 11,80 & 5,67 & 8,56 & 9,92 & 7,72 & 9,11 \\
\hline
\end{tabular}

9. Operational power reserve using daily charts of 12 months (Figure 2, left), normative IA $J_{\mathbb{\Delta}_{j}}^{\text {onr. }}=0.004$ for the conditions of accounting dependence scheduled and unscheduled repairs

\begin{tabular}{|c|c|c|c|c|c|c|c|c|}
\hline Power reserve, & MW & 10500 & 3486 & 470 & 991 & 1102 & 2306 & 2144 \\
\hline & $\%$ & 6,74 & 9,32 & 2,75 & 5,89 & 7,28 & 5,87 & 7,12 \\
\hline
\end{tabular}

The domestic probabilistic indicator of adequacy in the

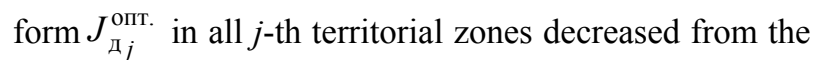
normative value of 0.0042 to 0.00082 , foreign $L O L H$ from 36 hours to $7.25 \mathrm{~h}$.

It is clear, and this has already been written above, that the results presented are obtained with a conditional representation of the electricity consumption regime. To these conventions it is possible to carry not absolutely correct representation of seasonal reduction of loading, its casual deviations, the account of days off and holidays, the account of capital repairs and many other things. Nevertheless, the experience of calculations shows that these conventions will not have much effect on those given in line 4 of Table 1 results. This again suggests that a change in the representation of the power consumption regime should lead to a change in the normative indicator of adequacy.

The next two lines ( 8 and 9) characterize the distribution of the operational (compensation) power reserve in the UPS of Russia, obtained by changing the indicators of adequacy of the composition of the 
generating equipment taken into account (the third moment). In the calculations given in these lines, the composition of the generating equipment was determined based on the conditions for exceeding the generating power corresponding to the composition considered above the load on the component of the operational (compensation) power reserve. Such a composition in real conditions is not so easy to pick up, so certain assumptions were made. In this regard, much can be more correctly implemented when using retrospective information on the conduct of long-term power debits ${ }^{4}$.

It should be noted that taking into account the actual composition of the generating equipment in the construction of binominal series of probabilities of emergency power reduction leads to an almost percentage reduction in the operational (compensation) power reserve. This reduction in the power reserve exceeds by more than a quarter the mathematical expectation of the generated generating equipment (power surpluses, planned repairs) from the total available composition corresponding to the installed power of the territorial zones of the UPS of Russia. Naturally, this feature of the presentation of generating equipment should be taken into account when justifying the operational power reserve of the territorial zones of the UPS of Russia.

\section{Main findings}

- The significant influence of the representation of the annual power consumption regime on the estimation of the indicators of adequacy the territorial zones of the UPS of Russia and their means of providing - power reserv.

- The change in the principle of accounting for the electricity consumption regime from one daily average schedule for December for 250 working days of the year for all 8760 hourly load changes will lead to a change in the normative indicator of adequacy adopted in the 2003 guidelines as an integral probability of failure-free operation $\bar{\rho}=0.996$. Studies show that the most acceptable standard values of indicators of adequacy can be taken in Western European countries $L O L H=3 \div 8$ hours, or in translation to the probabilistic index $\bar{\rho}=0.9991 \div 0.9997$.

- In modern conditions, the presence of large surplus power in the UPS of Russia and the transition to scheduled repairs of generating equipment by its condition when justifying the operational (compensatory) component of the normative (full) power reserve, it is necessary to approach more strictly the definition of the actual composition of the generating equipment.

\footnotetext{
${ }^{4}$ Decree of the Government of the Russian Federation of December 27, 2010, No. 1172 (Edited on 19.01.2018) "On Approval of the Rules for the Wholesale Electricity and Capacity Market and on Amending Certain Acts of the Government of the Russian Federation on the Organization of the Wholesale Electricity and Capacity Market".
}

\section{References}

1. Methodical recommendations on designing the development of power systems. (Approved by Order of the Ministry of Energy of Russia of June 30, 2003, No. 281). - M: Ministry of Energy of the Russian Federation, SO 153-34.20.118-2003.

2. Wolkenau IM, Zeyliger AN, Khabachev LD Economics of the formation of electric power systems. Moscow: Energoatomizdat. 1981. - 320 s.

3. Volkov G.A. Optimization of reliability of electric power systems. - Moscow: Nauka, 1986. - 117 p.

4. Kovalev GF, Lebedeva LM Reliability of power systems. - Novosibirsk: Science, 2015. - 224 p.

5. Chukreev Yu.Ya. Models for ensuring the reliability of electric power systems. - Syktyvkar: Komi Scientific Center of the UrB RAS, 1995.-176 p.

6. Chukreev Yu.Ya., Chukreev M.Yu. Models for estimating the indicators of balance reliability in the management of the development of electric power systems. - Syktyvkar: Komi Scientific Center of the Ural Branch of the Russian Academy of Sciences, 2014. $207 \mathrm{p}$.

7. Billinton R., Allan R.N. Reliability Evaluation of Power Systems. Second Edition. New York and London, Plenum Press, 1996. 509 p.

8. Chukreev Yu.Ya. Provision of balance reliability in relation to the current conditions of long-term planning of the UPS of Russia // Methodological issues of reliability research of large energy systems. Issue.68. Irkutsk: Research and provision of reliability of energy systems - ISEM SB RAS, 2017. - P. 56-65. 